\section{Commentary: Aortic stenosis in young patients - planning a lifetime of aortic valve disease}

\author{
J. James Edelman, MBBS(Hons), PhD, ${ }^{\mathrm{a}}$ \\ Christopher U. Meduri, MD, MPH, ${ }^{\mathrm{b}}$ and \\ Vinod H. Thourani, MD
}

There has been enthusiasm for extending the use of transcatheter aortic valve replacement (TAVR) to lower-risk patient populations over the last decade. This has been fueled by the excellent results following TAVR in trials comparing it with surgical aortic valve replacement (SAVR) in the mid-term (5 years) for intermediate-risk patients (V.H. Thourani, personal communication, Transcatheter Cardiovascular Therapeutics 2019, San Francisco, Calif) and at 1 year in low-risk patients. ${ }^{1,2}$ The mean age of patients in these trials was approximately 82 and 74 years, respectively, and these patients are unlikely to require reintervention, assuming the durability of TAVR valves is similar to SAVR. In August 2019, the Food and Drug Administration approved TAVR for use in low-risk patients, regardless of age or valve morphology.

There has been little discussion about the lifetime management of aortic stenosis in patients expected to outlive the durability of their bioprosthesis, in either the surgical or transcatheter literature. There has been a steady increase in the number of bioprostheses compared with mechanical prostheses over the past decade for younger patients undergoing SAVR. ${ }^{3}$ Before the commercial introduction of valve-in-valve TAVR, the rationale for this was that the risk of redo surgery may be lower than the lifetime risk of bleeding on warfarin required for a mechanical valve. ${ }^{4}$ An increasing amount of data supporting the safety of TAVR valve-in-valve, especially in surgical valves $>23 \mathrm{~mm}$, where the risk of coronary

From the ${ }^{a}$ Department of Cardiothoracic Surgery, Fiona Stanley Hospital, Perth, Australia; and Departments of ${ }^{\mathrm{b}}$ Cardiology and ${ }^{\mathrm{c} C}$ ardiovascular Surgery, Marcus Valve Center, Piedmont Heart Institute, Atlanta, Ga.

Disclosures: Authors have nothing to disclose with regard to commercial support.

Received for publication Dec 30, 2019; accepted for publication Dec 31, 2019; available ahead of print Jan 11, 2020.

Address for reprints: Vinod H. Thourani, MD, Department of Cardiovascular Surgery, Piedmont Heart Institute, 95 Collier Rd, Suite 5015, Atlanta, GA 30308 (E-mail: vinod.thourani@piedmont.org).

J Thorac Cardiovasc Surg 2021;162:548-9

$0022-5223 / \$ 36.00$

Copyright (c) 2020 by The American Association for Thoracic Surgery

https://doi.org/10.1016/j.jtcvs.2019.12.095

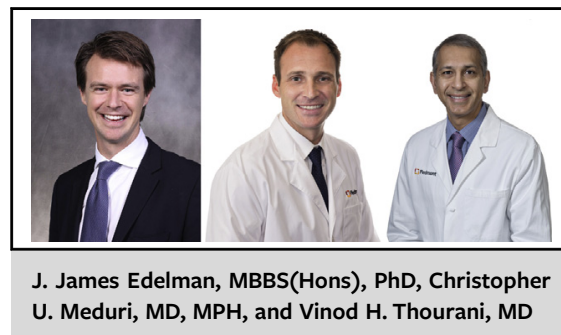

\section{CENTRAL MESSAGE \\ Surgical removal of TAVR valves is challenging and may be associated with high mortality. Young pa- tients with aortic stenosis require a discussion about the lifetime management of their disease.}

obstruction is low, supports this trend. ${ }^{5}$ However, an initial strategy of TAVR in young patients, who are expected to outlive (at least) one bioprosthesis, requires additional thought and further data.

In this issue of the Journal, Fukuhara and colleagues ${ }^{6}$ describe the first series of surgical explantation of TAVR valves. The rate of explantation is very smallapproximately $1 \%$ of the University of Michigan's TAVR experience-but highlights the technical difficulties in what may become a common problem in the future. Severe paravalvular regurgitation was the most common indication for TAVR explant, followed by structural valve deterioration and endocarditis. Mortality was $11 \%$; importantly, the mortality risk of patients who returned for TAVR explant more than doubled their risk at initial valve implantation. Aortic endarterectomy of valve struts, unplanned need for aortic root replacement, and injury to the anterior leaflet of the mitral valve are more likely in surgical explant of TAVR valves than redo-aortic valve replacement.

There is a paradigm shift in treatment of aortic valve disease that will result in younger patients being treated with TAVR. Although the rate of moderate or severe paravalvular leak is decreasing with newer-generation TAVR prostheses, the absolute numbers of patients requiring surgical explant of TAVR valves for structural valve deterioration and endocarditis will increase as more TAVR valves are placed in younger patients. A discussion involving the lifetime management of a young patient's aortic valve disease must be had if TAVR is chosen as their initial valve strategy and must be done with an understanding of individual patient anatomy. The absence of any outcome data for TAVR-in-TAVR should be acknowledged, especially 
in light of the data that the most common SAVR valve implanted in the United States is a 21-mm valve. This series from Michigan provides reference to discuss the significant challenges of surgical explantation of TAVR valves. It is also important to surgeons that an initial strategy of SAVR, with a large-sized bioprosthesis and even potential root enlargement, followed by TAVR valve-in-valve may be the safest strategy for young patients with aortic valve disease.

\section{References}

1. Mack MJ, Leon MB, Thourani VH, Makkar R, Kodali SK, Russo M, et al, Transcatheter aortic-valve replacement with a balloon-expandable valve in low-risk patients. N Engl J Med. 2019;380:1695-705.
2. Popma JJ, Deeb GM, Yakubov SJ, Mumtaz M, Gada H, O'Hair D, et al Transcatheter aortic-valve replacement with a self-expanding valve in low-risk patients. N Engl J Med. 2019;380:1706-15.

3. Brown JM, O'Brien SM, Wu C, Sikora JAH, Griffith BP, Gammie JS. Isolated aortic valve replacement in North America comprising 108,687 patients in 10 years: changes in risks, valve types, and outcomes in the Society of Thoracic Surgeons National Database. J Thorac Cardiovasc Surg. 2009;137: 82-90.

4. Zhao DF, Seco M, Wu JJ, Edelman JB, Wilson MK, Vallely MP, et al. Mechanica versus bioprosthetic aortic valve replacement in middle-aged adults: a systematic review and meta-analysis. Ann Thorac Surg. 2016;102:315-27.

5. Edelman JJ, Khan JM, Rogers T, Shults C, Satler LF, Itsik Ben-Dor I, et al Valve-in-valve TAVR: state-of-the-art review. Innovations (Phila). 2019;14: 299-310.

6. Fukuhara S, Brescia A, Shiomi S, Rosati CM, Yang B, Kim KM, et al. Surgical explantation of transcatheter aortic bioprostheses: results and clinical implications. J Thorac Cardiovasc Surg. 2021;162:539-47.e1.

\title{
Commentary: Good information is the best medicine
}

\author{
Jay K. Bhama, MD
}

Dr Michael E. DeBakey said it best when he declared, "Good information is the best medicine." In our quest to balance our desire to offer cutting-edge technologies to our patients while also maintaining a very high standard of care, this statement remains a guiding principle.

In this issue of the Journal, Fukuhara and colleagues ${ }^{1}$ provide us both a unique perspective as well as some "good information" on the role of transcatheter aortic valve replacement (TAVR) in the primary management of patients with aortic valve stenosis. The study details their experience with 17 patients who required surgical explant of their TAVR valve for a variety of clinical reasons. Two major points are made. First, they point out that the technical challenges associated with removal of the TAVR prosthesis become more complicated

\footnotetext{
From the Department of Cardiothoracic Surgery \& Baptist Heart Failure and Transplant Institute, Baptist Health Medical Center; and Division of Cardiovascular Surgery, University of Arkansas for Medical Sciences, Little Rock, Ark.

Disclosures: Author has nothing to disclose with regard to commercial support.

Received for publication Dec 6, 2019; revisions received Dec 6, 2019; accepted for publication Dec 8, 2019; available ahead of print Jan 3, 2020.

Address for reprints: Jay K. Bhama, MD, Department of Cardiothoracic Surgery \& Heart Failure and Transplant Institute, Baptist Health Medical Center, 9601 Baptist Health Dr, Suite 990, Little Rock, AR 72205 (E-mail: bhamajk@me.com).

J Thorac Cardiovasc Surg 2021;162:549-50

$0022-5223 / \$ 36.00$

Copyright (C) 2019 by The American Association for Thoracic Surgery

https://doi.org/10.1016/j.jtcvs.2019.12.036
}

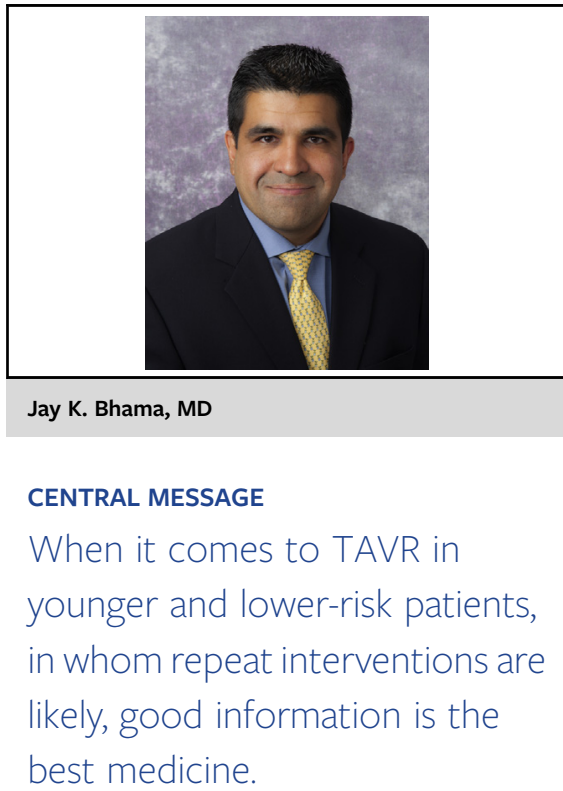

when the device has been implanted for more than a year, often requiring complex aortic root repair. Second, they demonstrate that these patients are at nearly 3 -fold greater predicted risk for mortality when they represent for explant of their device compared with when the device is implanted.

These findings are nascent and quite relevant, as there have been very few reports detailing the fate of failed TAVR prosthesis, especially from the surgical vantage point. As a consequence of this vacuum of data, there are numerous assumptions made at the time of initial TAVR therapy, both by cardiologists and surgeons, regarding the downstream management of the failed TAVR prosthesis. 